\title{
Evaluasi Kualitas Aplikasi Pengarsipan Surat pada PAUD Terpadu Inklusi Nur Ramadhan Banjarmasin dengan Metode Webqual 4.0 dan Importance Performance Analysis (IPA)
}

\author{
Andry Fajar Zulkarnain1, Yanuary Yulistian Putra ${ }^{2}$ \\ 1,2Program Studi Teknologi Informasi, Fakultas Teknik \\ ${ }^{1,2}$ Universitas Lambung Mangkurat, Jl. Brigadir Jenderal H. Hasan Basry, Banjarmasin \\ Email: andry.zulkarnain@ulm.ac.id ${ }^{1}$, yanuaryyulistian@gmail.com²
}

\begin{abstract}
ABSTRAK
Dalam melakukan evaluasi terhadap aplikasi pengarsipan surat di PAUD terpadu inklusi Nur Ramadhan dari persepsi pengguna, aplikasi yang dirasakan bersifat aktual dengan tingkat harapan ideal sehingga diketahui atribut atau fitur-fitur aplikasi yang sudah baik atau yang perlu dilakukan perbaikan. Penggunaan metode WebQual 4.0 digunakan untuk mengukur tingkat kualitas aplikasi dengan variabel penilaian yang lebih sedikit akan tetapi jumlah responden yang digunakan lebih banyak agar mendapatkan hasil yang maksimal. Metode WebQual 4.0 juga diikuti penilaian melalui usability, information dan service quality agar bisa memenuhi kebutuhan untuk pengukuran sebuah aplikasi. Metode IPA diaplikasikan untuk membantu dalam analisis dan pengolahan data. Hasil perhitungan WebQual Index (WQI) menunjukkan bahwa aplikasi pengarsipan surat berbasis website sudah memiliki kualitas yang baik serta dengan teknik Importance Performance Analysis (IPA) menunjukkan bahwa aplikasi pengarsipan surat berbasis memiliki 9 (sembilan) indikator yang dipertahankan kualitasnya karena sudah memenuhi harapan konsumen dan 3 (tiga) indikator harus menjadi prioritas perbaikan.
\end{abstract}

Kata Kunci: Webqual 4.0, Importance Performance Analysis, PAUD Terpadu Inklusi Nur Ramadhan Banjarmasin, Evaluasi

\section{ABSTRACT}

In evaluating the letter applying for the integrated PAUD inclusion of Nur Ramadhan from user perceptions, the perceived application is actual with an ideal level of expectation so that attributes or features are known that are good or that need improvement. The WebQual 4.0 method is used to measure the level of quality of the application with fewer variables. Still, the number of respondents used is more to get maximum results. The WebQual 4.0 method also follows production through usability, information, and service quality to meet the needs for measuring an application. The IPA method is applied to assist in data analysis and processing. The results of the calculation of the WebQual Index (WQI) show that the web-based letter archiving application is of good quality, and the Importance Performance Analysis (IPA) technique shows that the letter-based filing application has 9 (nine) indicators that are maintained quality because it meets consumer expectations and 3 (three) indicators must be a priority for improvement. 
Keywords: Webqual 4.0, Importance Performance Analysis, PAUD Terpadu Inklusi Nur Ramadhan Banjarmasin, Evaluation

\section{PENDAHULUAN}

Di era modern sekarang ini hampir semua bidang aspek kegiatan ditentukan oleh teknologi. Salah satu teknologi yang harus bisa dioperasikan adalah komputer. Komputer sebagai salah satu teknologi saat ini yang meluas dan sangat dibutuhkan di berbagai lingkungan kerja.

Kemajuan di dalam bidang komputer yang sangat pesat,maka tidak mengherankan lagi banyak instansi pemerintah yang memanfaatkan komputer di dalam meningkatkan kinerjanya. Salah satunya adalah aplikasi berbasis aplikasi pengarsipan surat di paud terpadu inklusi Nur Ramadhan.

Aplikasi berbasisi Aplikasi merupakan sebuah aplikasi yang dapat diakses menggunakan web browser atau penjelajah web melalui jaringan internet. Meskipun hingga saat ini ternyata lebih banyak, lebih luas, dan lebih komersil dalam pemakaiannya. Banyak dari perusahaan-perusahaan berkembang yang menggunakan aplikasi berbasis web dalam merencanakan sumber daya mereka dan untuk mengelola perusahaan mereka. (Irawan 2012) Beberapa yang lain mendefinisikan bahwa pengertian aplikasi web adalah program yang tersimpan pada server kemudian dikirim melalui internet dan diakses melalui antar muka atau interface berupa web browser.

Berdasarkan penjelasan di atas, maka dapat diterjemahkan secara bebas bahwa aplikasi berbasis web merupakan sebuah aplikasi yang diakses melalui web browser dengan menggunakan jaringan sebagai media transmisi. Aplikasi web juga merupakan sebuah perangkat lunak atau software yang di kodekan dengan bahasa pemogramman seperti html, javascript, css, ruby, python, php, dan bahasa pemogramman lainnya. Aplikasi berbasis web dapat digunakan untuk berbagai macam tujuan yang berbeda. (Andry, Christianto, and Wilujeng 2019)

Untuk meningkatkan kualitas aplikasi ini dirasa perlu agar dilakukan evalusi dengan menggunakan metode Webqual 4.0 dan Importance Performance Analysis (IPA), metode ini bertindak sebagai instrument yang menilai kualitas suatu aplikasi berdasarkan perspektif pengguna akhir dengan variabel penilaian yang lebih sedikit akan tetapi jumlah responden yang digunakan lebih banyak agar hasil yang didapatkan 
maksimal. Sedangkan metode IPA digunakan untuk membantu dalam analisis dan pengolahan data. (Nurma Yunita 2013)

Tujuan dari penelitian ini adalah analisis terhadap setiap variabel WebQual dan menunjukkan analisa kesesuaian antara persepsi pengguna dan harapan penggunaa. Hal ini diharapkan dapat memberikan feedback terhadap pihak manajemen (tim pengelola) layanan aplikasi pengarsipan surat di paud terpadu inklusi Nur Ramadhan.dalam perbaikan dan pengembangan aplikasi agar dapat meningkatkan kualitas aplikasi pengarsipan surat di paud terpadu inklusi Nur Ramadhan sesuai harapan penggunanya.

\section{METODE PENELITIAN}

\section{A. Kuisioner}

Penyebaran kuisioner dilakukan menggunakan metode slovin. Metode slovin adalah sebuah metode untuk menghitung jumlah sampel minimal apabila perilaku dari sebuah populasi tidak diketahui secara pasti.(Al-Bahri and Ismail 2019) Berikut ini adalah rumus atau formula untuk menentukan ukuran sampel menggunakan metode slovin. [14].

$$
\frac{N}{\left(1+\left(N \times d^{2}\right)\right.} \text { dimana } \mathrm{n}=\text { sampel, } \mathrm{N}=\text { populasi, } \mathrm{d}=\text { nilai presisi }
$$

Pada penelitian ini akan diambil sampel dari total responden sebanyak 45 orang yang terbagi menjadi 4 kate-gori yaitu GuruPAUD sebanyak 15 orang responden, Pegawai Tata Usaha sebanyak 5 orang responden, Mahasiswa PPL5 orang responden dan Orang tua murid sebanyak 20 responden. Tingkat kesalahan yang diambil adalah sebesar 5\%, maka jumlah sampel yang digunakan adalah:

$$
n=\frac{45}{\left(1+\left(70 \times 0,05^{2}\right)\right.}=\frac{45}{(1.1125)}=40,45
$$

\section{B. Webqual Index}

WebQual Index (WQI), adalah sebuah hasil berupa angka dari penelitian yang dilakukan untuk melihat kualitas dari sebuah sistem. Hasil dari WQI memerlukan beberapa data - data sebagai pelengkap, seperti weighted score (WS) dan juga maximum score (MS). Untuk nilai WQI didapat dengan menggunakan rumus dibawah ini: (Diana Apriliani, Muhammad Fikry 2020)

$$
W Q I=\sum \frac{W S}{M S} \text { maka } W Q I=\frac{14,41}{12,915,37}=0,94
$$




\section{Importance Performance Analisis (IPA)}

Importance Performance Analisis (IPA) digunakan untuk mengetahui sebab yang perlu dipertahankan dan yang memerlukan peningkatan serta faktor yang perlu diperhatikan untuk peningkatan kualitas pada sebuah aplikasi untuk kedepannya serta mengetahui hal-hal apa saja yang diinginkan oleh user dari suatu aplikasi, selain itu mengetahui tingkat kesesuaian antara kepuasan harapan dengan persepsi di masingmasing atribut.(Nada and Wibowo 2015) Nilai persepsi dan harapan didapat dari ratarata jawaban dari total responden. Kemudian hasil analisa tingkat kesesuaian akan dibuatkan diagram kartesius. Berikut ini merupakan tabel tingkat kepuasan harapan dan persepsi responden. (Muryadi 2017)

\section{Analisis Data}

Pada tahap analisis data, langkah pertama adalah studi literatur, tahap kedua pengumpulan data, tahap ketiga yaitu pengambilan sampel dengan cara judgment sampling (berdasarkan kriteria yang diinginkan) yaitu pengguna berdasarkan kategori yang sudah ditentukan sebelumnya dengan batasan usia minimal 17 tahun atau pengguna yang sudah memiliki KTP. Hal tersebut bertujuan agar pengguna dapat memberikan data penilaian secara bijak dan objektif yang selanjutnya data tersebut akan dilakukan analisa menggunakan metode WebQual dan Importance-Performance Analysis. (Muhsin and Zuliestiana 2017)

Adapun proses berjalannya penelitian ini dapat digambarkan dengan sederhana melalui flowchart berikut ini: 


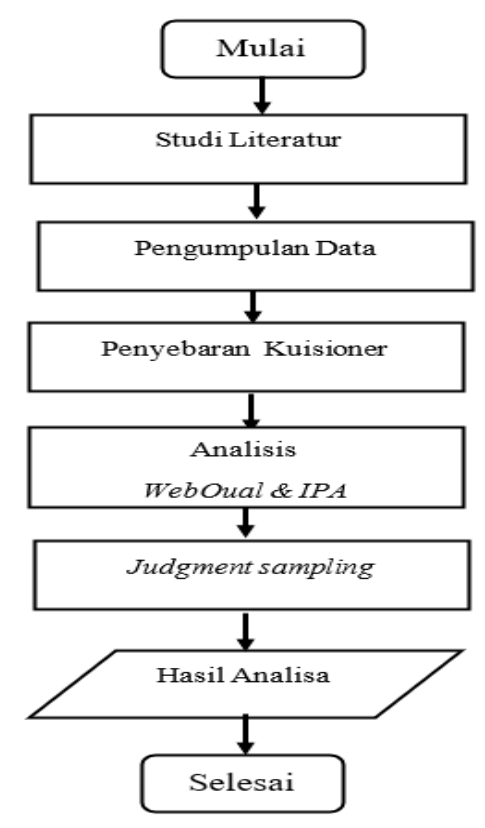

Gambar 1: Flowchart Penelitian

Terdapat 3 variable di dalam metode WebQual untuk menentukan kuisioner berdasarkan pengambilan sample, 3 variable itu adalah usability, information, dan service information. Ketiganya di tetapkan menjadi 22 indikator dan kemudian akan di bedakan lagi menjadi dua jenis, yaitu kualitas layanan yang saat ini di rasakan (performance) dan kualitas yang di harapkan atau pentingnya kualitas layanan untuk pengembangan (importance), yang digunakan dalam metode Importance-Performance Analisys (IPA).

\section{HASIL DAN PEMBAHASAN}

A. Gambaran Umum Sistem

Sistem Informasi Pengarsipan Surat Berbasis web di PAUD Terpadu Inklusi Nur Ramadhan ini digunakan untuk memudahkan dalam melakukan arsip surat masuk dan surat keluat pada PAUD Terpadu Inklusi Nur Ramadhan.

Aplikasi Pembuatan Rancang Bangun Sistem Informasi Pengarsipan Surat Berbasis web di PAUD Terpadu Inklusi Nur Ramadhan ini dapat membantu kelancaran dan meningkatkan efisiensi kerja bagi staf laporan dan data arsip surat masuk dan keluar, hasil dari sistem ini lebih efektif dan efisien serta penyimpanan data menjadi lebih rapi dan mudah diperbaharui. Gambar 4.1 Merupakan Tampilan Beranda dari Aplikasi Pengarsipan pada PAUD Inklusi Nur Ramadhan Banjarmasin. 


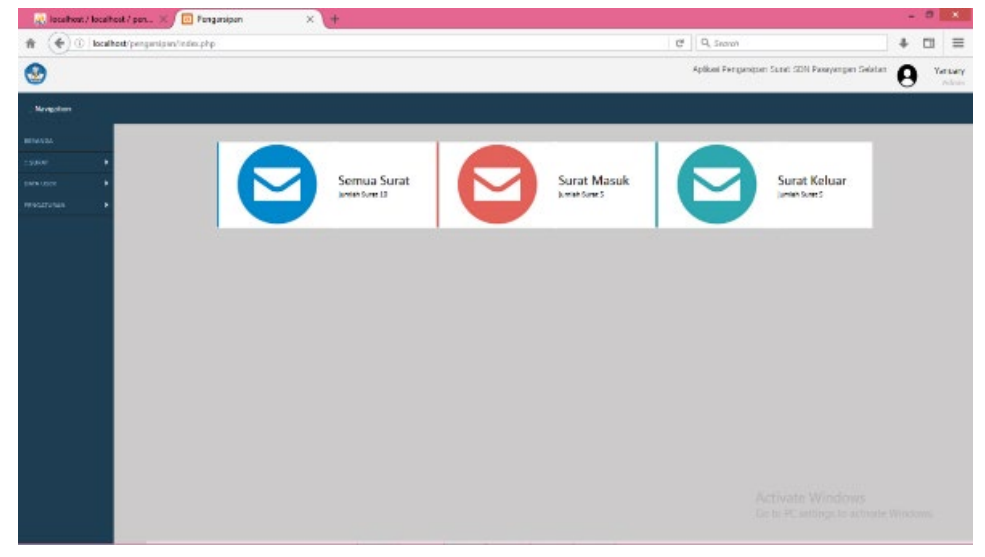

Gambar 2: Tampilan Beranda Aplikasi Pengarsipan Surat

B. Hasil Analisis

Pada proses ini ini akan dibahas hasil analisis dari data yang telah didapatkan. Analisis data dibagi menjadi tiga bagian yaitu Hasil Analisis Demografis, Analisis Hasil Uji Validitas dan Analisis Hasil Uji Reliabilitas. (Giyanti and Suparti 2018)Analisis data demografis dilakukan dengan menggunakan perangkat lunak Ms. Excel 2010, analisis demografis meliputi data profil responden. Sedangkan Analisis Hasil Uji Validitas dan Reliabilitas akan menggunakan bantuan perangkat lunak IBM SPSS 22.

\section{Hasil Uji Validitas}

Tabel 1. Hasil Uji Validitas Sampel dengan IBM SPSS 22

\begin{tabular}{|l|r|r|r|r|}
\hline \multicolumn{7}{|c|}{ Item-Total Statistics } \\
\hline & $\begin{array}{r}\text { Scale Mean if } \\
\text { Item Deleted }\end{array}$ & $\begin{array}{r}\text { Scale Vari- } \\
\text { ance if Item } \\
\text { Deleted }\end{array}$ & $\begin{array}{r}\text { Corrected Item- } \\
\text { Total Correla- } \\
\text { tion }\end{array}$ & $\begin{array}{r}\text { Cronbach's Al- } \\
\text { pha if Item De- } \\
\text { leted }\end{array}$ \\
\hline Q1 & 43.7561 & 64.139 & .443 & .886 \\
Q2 & 43.6585 & 64.530 & .475 & .885 \\
Q3 & 43.6098 & 64.894 & .425 & .886 \\
Q4 & 43.6829 & 64.122 & .551 & .883 \\
Q5 & 43.5122 & 64.556 & .418 & .886 \\
Q6 & 43.4878 & 65.456 & .406 & .886 \\
Q7 & 43.5122 & 64.756 & .350 & .888 \\
Q8 & 43.5122 & 65.756 & .355 & .887 \\
\hline Q9 & 43.6829 & 64.422 & .440 & .886 \\
Q10 & 43.7805 & 62.826 & .530 & .883 \\
Q11 & 43.6098 & 62.144 & .632 & .898 \\
\hline Q12 & 43.7317 & 70.701 & & .181 \\
\hline
\end{tabular}




\begin{tabular}{|l|r|r|r|r|}
\hline \multicolumn{7}{|c|}{ Item-Total Statistics } \\
\hline & $\begin{array}{c}\text { Scale Mean if } \\
\text { Item Deleted }\end{array}$ & $\begin{array}{c}\text { Scale Vari- } \\
\text { ance if Item } \\
\text { Deleted }\end{array}$ & $\begin{array}{r}\text { Corrected Item- } \\
\text { Total Correla- } \\
\text { tion }\end{array}$ & $\begin{array}{r}\text { Cronbach's Al- } \\
\text { pha if Item De- } \\
\text { leted }\end{array}$ \\
\hline Q13 & 43.4878 & 61.506 & .628 & .880 \\
Q14 & 43.5122 & 61.406 & .621 & .881 \\
Q15 & 43.5610 & 62.552 & .551 & .883 \\
Q16 & 43.5854 & 65.099 & .384 & .887 \\
Q17 & 43.5610 & 64.552 & .421 & .886 \\
Q18 & 43.5366 & 64.505 & .520 & .884 \\
Q19 & 43.6585 & 62.030 & .655 & .880 \\
Q20 & 43.6341 & 62.938 & .619 & .881 \\
Q21 & 43.6585 & 63.480 & .480 & .885 \\
Q22 & 43.6341 & 63.338 & .503 & .884 \\
\hline Q23 & 43.5122 & 64.156 & .361 & .888 \\
\hline Q24 & 43.3415 & 62.230 & .696 & .879 \\
\hline
\end{tabular}

\section{WebQual Index (WQI)}

WebQual Index (WQI), adalah sebuah angka hasil penelitian yang digunakan untuk melihat kualitas suatu sistem. Untuk mencari WQI diperlukan beberapa data pelengkap, seperti weighted score (WS) dan juga maximum score (MS). WQI sendiri memiliki skala mulai dari 0 sampai 1 , dimana nilai yang semakin mendekati 1 maka semakin baik kualitasnya. Untuk nilai WQI dapat diperoleh dengan menggunakan rumus sebagai berikut:

$$
W Q I=\sum \frac{W S}{M S} \quad \text { maka } \quad W Q I=\frac{14,41}{12,915,37}=0,94
$$

Berdasarkan hasil perhitungan diatas, indikator pertama mendapatkan nilai WQI sebesar 0,94 yang mana mendekati angka 1 sehingga indikator tersebut bisa dikatakan berkualitas baik.

\section{E. Importance Performance Analisis (IPA)}

Importance Performance Analisis (IPA) digunakan guna melihat faktor-faktor yang perlu dipertahankan dan yang ditingkatkan serta faktor yang perlu mendapat perhatian utama untuk peningkatan kualitas Aplikasi kedepannya serta mengetahui hal-hal apa saja yang diinginkan oleh pengguna dari Aplikasi, selain itu mengetahui tingkat kesesuaian antara kepuasan harapan dengan persepsi di masing-masing atribut. Nilai 
persepsi dan harapan didapat dari rata-rata jawaban dari total responden. Kemudian hasil analisa tingkat kesesuaian akan dibuatkan diagram kartesius. Berikut ini merupakan tabel tingkat kepuasan harapan dan persepsi responden.

Berdasarkan data analisa maka akan dibuat diagram kartesius untuk mengetahui tingkat kesesuaian antara kepuasan harapan dengan persepsi di masing-masing atribut.

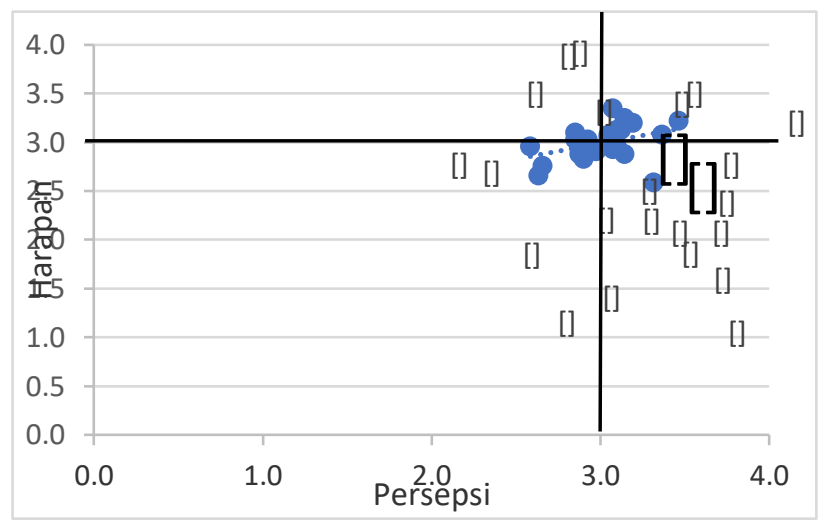

Gambar 2: Hasil Kuadran Importance Performance Analisis (IPA)

Berdasarkan Gambar diatas dapat dilihat hasil dari kuadaran IPA terdapat 9 atribut pada kuadran I dimana atribut tersebut harus dipertahankan kualitasnya karena sudah memenuhi harapan konsumen. Sedangkan pada kuadran II terdapat 3 atribut yang mana atribut tersebut harus menjadi prioritas perbaikan. Kemudian pada kuadran III terdapat 8 atribut, akan tetapi atribut-atribut tersebut tidak memerlukan perbaikan yang signifikan karena harapan pengguna pada atribut ini tidak terlalu tinggi. Kemudian yang terakhir pada kuadran IV terdapat 4 atribut dimana atribut-atribut ini dianggap tidak terlalu penting namun memiliki kualitas yang baik, sehingga perhatian terhadap atribut ini bisa dialihkan ke atribut lain yang lebih membutuhkan.

\section{SIMPULAN}

1. Pada penelitian ini, dilakukan pengukuran untuk mengetahui kualitas dari Aplikasi pengarsipan surat berbasis Website pada PAUD Nur Ramadhan Banjarmasin

2. Hasil perhitungan WebQual Index (WQI) menunjukkan bahwa Aplikasi pengarsipan surat berbasis Website pada PAUD Nur Ramadhan Banjarmasin memiliki kualitas yang baik

3. Analisis dengan menggunakan teknik Importance-Performance Analysis menunjukkan bahwa Aplikasi pengarsipan surat berbasis Website pada PAUD Nur Ramadhan Banjarmasin memiliki 9 indikator/atribut yang paling banyak untuk 
dipertahankan kualitasnya karena sudah memenuhi harapan konsumen dan 3 indikator/atribut yang harus menjadi prioritas perbaikan

4. Hasil dari penelitian ini dapat dijadikan manajemen sebagai acuan untuk melakukan perbaikan dan peningkatan serta pengembangan aplikasi dengan memfokuskan pada atribut-atribut yang menjadi prioritas perbaikan.

\section{DAFTAR PUSTAKA}

Al-Bahri, Fauzan Putraga, and Ismail. 2019. "WebQual 4.0 Dan ImportancePerformance Analysis (IPA): Eksplorasi Kualitas Situs Web e-Kuisioner." Jurnal JTIK (Jurnal Teknologi Informasi dan Komunikasi) 3(2).

Andry, Johanes Fernandes, Kevin Christianto, and Fuji Rahayu Wilujeng. 2019. "Using Webqual 4.0 and Importance Performance Analysis to Evaluate E-Commerce Website." Journal of Information Systems Engineering and Business Intelligence 5(1): 23.

Diana Apriliani, Muhammad Fikry, Marnala J. Hutajulu. 2020. “Analisa Metode Webqual 4 .0 Dan Importance- Performance Analysis ( IPA ) Pada Kualitas Situs Detik.Com." Jurnal Ilmiah Merpati 8(1): 34-45.

Giyanti, Ida, and Erni Suparti. 2018. "Penilaian Kualitas Aplikasi Halal MUI Dengan WEBQUAL 4.0 Dan Pengaruhnya Terhadap Keputusan Penggunaan.” J@ ti Undip: Jurnal Teknik Industri 13(2): 91-98.

Irawan, Candra. 2012. "Evaluasi Kualitas Website Pemerintah Daerah Dengan Menggunakan WebQual (Studi Kasus Pada Kabupaten Ogan Ilir).” JSI: Jurnal Sistem Informasi (E-Journal) 4(2).

Muhsin, Ali, and Dinda Amanda Zuliestiana. 2017. "Analisis Pengaruh Kualitas Website (Webqual) 4.0 Terhadap Kepuasan Pengguna Bukalapak Di Kota Bandung." eProceedings of Management 4(3).

Muryadi, Agustanico Dwi. 2017. "Model Evaluasi Program Dalam Penelitian Evaluasi." JURNAL ILMIAH PENJAS (Penelitian, Pendidikan dan Pengajaran) $3(1)$.

Nada, Noora Qotrun, and Setyoningsih Wibowo. 2015. "Pengukuran Kualitas Layanan Sistem Informasi Akademik Menggunakan Metode Webqual 4.0." Jurnal Informatika UPGRIS 1(2 Desember).

Nurma Yunita. 2013. "FAKTOR-FAKTOR YANG MEMPENGARUHI KUALITAS LAYANAN WEBSITE BANK SYARIAH TERHADAP PEROLEHAN INFORMASI NASABAH (STUDI BNI SYARIAH KOTA BOGOR)." Journal of Chemical Information and Modeling 53(9): 1689-99. 